\title{
OUTGROUP EVALUATION AND SOCIAL IDENTITY AMONG BOYS AND GIRLS AS RELATED TO PARENTAL OCCUPATION AND RESIDENCE
}

\author{
Nazma Afroz \\ Department of Psychology, University of Rajshahi, Rajshahi 6205, Bangladesh
}

\begin{abstract}
The study attempted to investigate social identity and out-group evaluation in adolescent boys and girls in relation to parental occupation and residential background. The study used a sample composed of 320 respondents. An Adjective Check List was used for data collection. A three way analysis of variance involving 2 levels of gender (boys/girls), 2 levels of parental occupation (business/service) and 2 levels of residence (urban/rural) was used for the computation of results. Results showed gender, parental occupation and residence had statistically significant effects on the respondents. A two-way interaction between profession and residence was also statistically significant. Respondents with service background evaluated out-group significantly less positively as compared to the respondents with business background. Again, girls evaluated out-group significantly less positively as compared to the boys. Moreover, respondents with urban residence evaluated out-group significantly less positively as compared to the respondents with rural residence.
\end{abstract}

Key words: Social identity, self-depreciation, parental occupation, misidentified perception, racial identification.

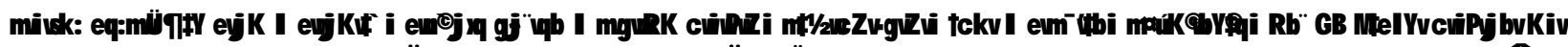

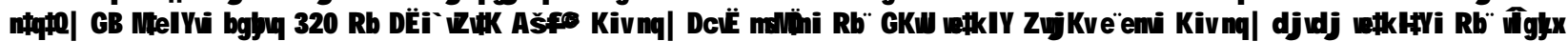

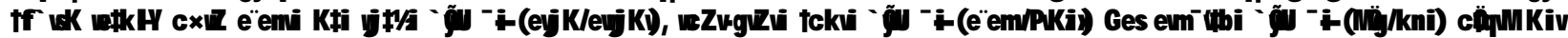

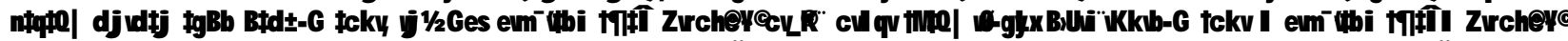

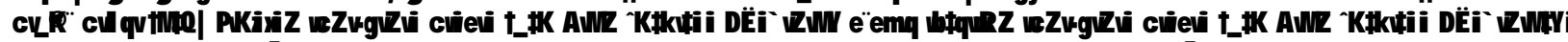

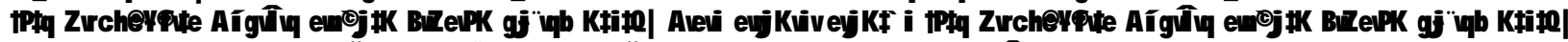

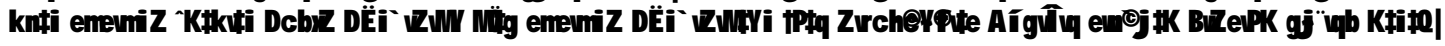

\section{Introduction}

Social identity involves inter-group relations. The concept of social identity is related with in-group and out-group evaluations. Basically social identity deals with racial categorization. But the concept of social identity may be used to understand various types of group categorization. A number of studies in the past showed various aspects of identity and inter-group behaviour in humans. Hogg et al. (1955) found that individual agents act by changing social arrangements to bring the self into line with the abstract prototypes or identity standard. Whereas according to Sherif (1966) social identity should be understood in terms of group identification and inter-group behaviour. Levine and Campbell (1972) provided historical and sociological coverage for group composition. Ehrlich (1973) mentioned that two types of theories are required to explain the state of ethnic group relation in a society. One must be a theory of inter-group behaviour, sociological in orientation and the other is social psychological. Kidder and Stewart (1975) tried to integrate between historical and sociological approaches of inter-group relations. Commins and Lockwood (1979) observed that the social group is seen to function as a provider of positive social identity for its members through comparing itself and distinguishing itself from other comparison groups along salient dimensions which have a clear value differential.

Billig (1971) and Tajfel (1978) defined social identity as the process by which any individual is bound by his social group and by which he realizes his social life. It is the part of the individual's self-concept which derives from the knowledge of the membership of social group or groups together with the value and emotional significance of that membership (Tajfel 1981). Tajfel (1981) also mentioned that social identity patterns would be assessed in relation to differences in owngroup and out-group evaluation of positive and negative adjectives. Thus, social identity of a social group provides meanings to group identification and social comparison. Social identity moulds the way in which even younger children come to think of themselves and their groups. This identity formation process is varied in its form and content. It is contingent upon its larger social context. The present study was an attempt to investigate the patterns of social identity of adolescent boys and girls in terms of out-group evaluations. The study was designed to find out the patterns of social identity affected by parental occupation and residential background. Thus, parental occupation and residential 
background were taken as independent variables and patterns of social identity in terms of out-group evaluations were taken as a dependent variable. Turner et al. (1987) showed that people behave so as to enhance the evaluation of the in-group relative to the out-group. The self-esteem motive is thought as the basis of in-group favouritism, ethnocentrism and hostility toward the out-group.

Recently Ethier and Deaux (1994) found that people behave in concert within a group with which they identity. In a low status minority group, the individuals participate in the group's culture for distinguishing themselves from the out-group. Stryker and Serpe (1994) mentioned that the greater the embeddedness of the identity in the social structure, the more likely it is that the identity will be activated in the situation. Stronger ties to others through an identity lead to a more salient identity. On the other hand, Freese and Burke (1994) found that the conceptions of in-group and out-group constitute the important area related to linking the individual in the form of social identity. Oakes et al. (1994) found that the basis of social identity is the uniformity of perceptions and action among group members. Here is the important distinction between ingroup favouritism and out-group discrimination. Haslam et al. (1996) demonstrated that stereotyped perceptions of in-group members and out-group members are enhanced and are made more homogeneous by identification with the in-group. Ellemers and Van Knippenberg (1997) reported that when the group's status is relatively low, the group members have less desire to lead the group and are negatively affected by out-group evaluations. They also found that one's self-esteem is enhanced by evaluating the in-group and the out-group or dimensions that lead the in-group to be judged positively and the out-group to be judged negatively.

\section{Rationale and hypotheses}

The present study attempted to investigate social identity and out-group evaluation in adolescent boys and girls in relation to parental occupation and residential background. However, specific rationales of the study include (i) to conduct an empirical study on social identity; (ii) to manipulate parental occupation and residence as independent variables; (iii) to find out the effects of parental occupation and residence on social identity in terms of out-group evaluations in adolescent boys and girls; and (iv) to compute the effects between different factors of parental occupation and residence on social identity in terms of out-group evaluations in adolescent boys and girls. Several predications made for this study were: $\mathbf{H}_{\mathbf{1}}$ : Adolescents reared in families of parents in service evaluate out- group members less positively as compared to those reared in the families of parents in business; $\mathbf{H}_{\mathbf{2}}$ : Adolescent girls evaluate out-group members less positively as compared to the adolescent boys; and $\mathbf{H}_{3}$ : Adolescents with urban residential background evaluate out-group less positively as compared to those with rural residential background.

\section{Materials and Methods}

Sample: The sample of the present study was composed of 320 respondents, equally divided into boys and girls. Each category was again divided into urban and rural on the basis of their residential background. They were again equally divided into service and business on the basis of their parental occupation. Thus the study involved a $2 \times 2 \times 2$ factorial design consisting of 40 respondents in each cell. In this study, those areas were regarded as urban areas where people enjoy all the advantages of science and technology, are enriched with the advantages of industrialization and where people live competitive lives with each other in daily living contexts and job sectors. On the other hand, those areas were regarded as rural areas where people have the insufficiency of science and technological facilities, lead traditional and simple lives, dependent on agriculture, have less competition among people and have mutual cooperation among them.

Instrument: An Adjective Check List (ACL) containing 24 bipolar adjectives, developed by Majeed and Ghosh (1982), was used as an instrument for data collection. Twelve of these adjectives were positive and the rest 12 were negative. The adjective used were as follows: 1) Clean-Dirty, 2) Religious-Atheist, 3) Benevolent-Selfcentered, 4) Sweet tongued-Rough tongued, 5) SimpleProudly, 6) Economical-Extravagant, 7) FriendlyEnemical, 8) Patriotic-Traitorous, 9) Industrious-Idle, 10) Heroic-Coward, 11) Peaceloving-Aggressive and 12) Cooperative-Competitive.

Data collection procedure: The investigator approached each respondent individually and asked him/her to read the ACL carefully. The instruction was given on the top of the ACL. Each respondent was asked to evaluate own-group and out-group separately, and thus two sets of evaluations were recorded for each respondent. As soon as the data collection was completed, the answer sheets were collected, and then coding was done properly for the preparations of results.

Scoring procedure: The respondents were asked to evaluate each adjective for own and out-group preferences on a five-point scale ranging from totally applicable to totally not applicable. A discrepancy (D) score was calculated by subtracting a positive score 
from a negative score on each item. A high score with plus (+) sign indicated more positive evaluation. A high score with minus (-) sign indicated more negative evaluation. No minus sign was obtained in their total evaluation and as such no constant was added to convert minus scores to positive numbers. In order to get statistical significance of the effects of independent variables, the $\mathrm{D}$ scores were subjected to a $2 \times 2 \times 2$ factorial ANOVA representing two levels of gender (boys/girls), two levels of parental occupation (business/service) and two levels of residential background (urban/rural). ANOVA was computed for out-group evaluation. In addition, pair-wise comparisons of group means were made using Newman-Keuls test.

\section{Results and Discussion}

Mean score evaluation: Mean scores on gender, parental occupation and residential background of the subjects are presented in Table 1. Results show that regardless of parental occupation and residence, girls $(\mathrm{M}=2.46)$ evaluated out-group significantly less positively as compared to boys ( $M=8.03)$, suggesting that preference for out-group was more positive for the boys compared to that for the girls. On the other hand, irrespective of gender and residence, respondents with parental service background $(M=4.05)$ evaluated outgroup significantly less positively as compared to the respondents with parental business background $(M=6.45)$, indicating that both groups with business and service background evaluated their out-group less positively but the respondents with service background were less positive in out-group evaluations. Moreover, regardless of parental occupation and gender, respondents with urban residential background $(M=2.60)$ evaluated out-group significantly less positively compared to their rural residential background counterparts $(M=7.90)$ which indicated that respondents with rural residential background evaluated out-group more positively than their urban residential background counterparts.

Table 1. Mean scores of ACL (Adjective Check List) on outgroup evaluation of 320 respondents

\begin{tabular}{lll}
\hline Variables & \multicolumn{2}{c}{ Mean scores } \\
\hline Gender & Boy & 8.03 \\
& Girl & 2.46 \\
& & \\
Parental occupation & Business & 6.45 \\
& Service & 4.05 \\
Residence & & \\
& Urban & 2.60 \\
& Rural & 7.90 \\
\hline
\end{tabular}

A further evaluation of the mean scores (Table 2) showed that urban respondents $(\mathrm{M}=1.80)$ evaluated their out-group significantly less positively compared to the rural respondents with business background $(\mathrm{M}=12.02)$. However, no significant mean difference was obtained in the out-group evaluations between the urban and rural respondents with service background. Between-group comparison showed that urban respondents with business background $(\mathrm{M}=1.80)$ evaluated the out-group significantly less positively as compared to the urban respondents with service background $(\mathrm{M}=4.33)$. But the rural respondents with service background $(M=3.77)$ evaluated out-group less positively as compared to rural respondents with business background $(\mathrm{M}=12.02)$. A twoway interaction effect, graphically shown in Fig 1, suggests that urban respondents with business background had the least positive evaluation. Then it increased gradually followed by rural respondents with service background, urban respondents with service background and rural respondents with business background.

Table 2. Significant mean differences for two-way interaction between parental occupation and residence on the scores of ACL on out-group evaluation in 320 respondents

\begin{tabular}{|c|c|c|}
\hline Occupation & Urban & Rural \\
\hline Business & $1.80^{\mathrm{a}}$ & $12.02^{\mathrm{b}}$ \\
\hline Service & $4.33^{\mathrm{c}}$ & $3.77^{\mathrm{C}}$ \\
\hline
\end{tabular}

Dissimilar superscripts differ significantly by NewmanKeuls test $(\mathrm{P}<0.05)$.

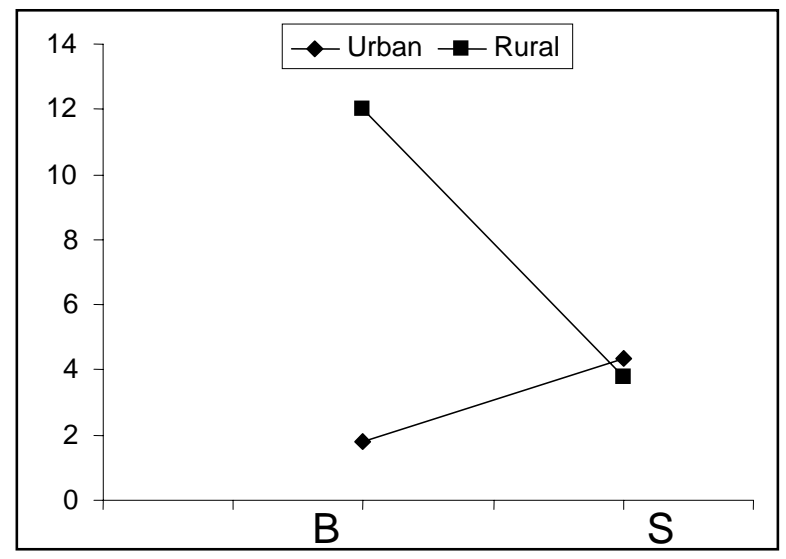

Fig. 1. A two-way interaction between parental occupation ( $\mathrm{B}=$ business vs. $\mathrm{S}=$ service) and residence (urban vs. rural) of the respondents.

Out-group evaluation: Analysis of variance on gender, parental occupation and residence computed for out-group evaluation of the ' $\mathrm{D}$ ' scores of the ACL (Table 3) revealed that all the independent variables viz. parental occupation 
$\left(\mathrm{F}_{1,312}=2.99 ; \mathrm{P}<0.05\right)$, gender $\left(\mathrm{F}_{1,312}=16.22 ; \mathrm{P}<0.01\right)$ and residential background $\left(\mathrm{F}_{1,312}=14.66 ; \mathrm{P}<0.01\right)$ were statistically significant, but the interactions among the three variables were insignificant except for the parental occupation and residence $\left(\mathrm{F}_{1,312}=16.17 ; \mathrm{P}<0.01\right)$.

Table 3. Analysis of variance table showing gender, parental occupation and residence for out-group evaluation on the D (discrepancy) scores of the ACL (Adjective Check List).

\begin{tabular}{|c|c|c|c|c|}
\hline $\begin{array}{c}\text { Sources of } \\
\text { variance }\end{array}$ & $\begin{array}{c}\text { Sum of } \\
\text { squares } \\
\text { (SS) }\end{array}$ & df & $\begin{array}{c}\text { Mean } \\
\text { squares } \\
\text { (MS) }\end{array}$ & F-values \\
\hline Gender (A) & 2480.88 & 1 & 2480.88 & $16.22^{* *}$ \\
\hline $\begin{array}{c}\text { Parental } \\
\text { occupation } \\
\text { (B) }\end{array}$ & 548.4 & 1 & 458.4 & $2.99^{*}$ \\
\hline $\begin{array}{c}\text { Residence } \\
(\mathrm{C})\end{array}$ & 2241.9 & 1 & 2241.9 & $14.66^{* *}$ \\
\hline $\mathrm{A} \times \mathrm{B}$ & 306.15 & 1 & 306.15 & $2.00 \mathrm{~ns}$ \\
\hline $\mathrm{A} \times \mathrm{C}$ & 306.15 & 1 & 306.15 & $2.00 \mathrm{~ns}$ \\
\hline $\mathrm{B} \times \mathrm{C}$ & 2473.66 & 1 & 2473.66 & $16.17^{* *}$ \\
\hline $\mathrm{A} \times \mathrm{B} \times \mathrm{C}$ & 310.09 & 1 & 310.09 & $2.20 \mathrm{~ns}$ \\
\hline $\begin{array}{c}\text { Within cells } \\
(\text { Error })\end{array}$ & 47703.27 & 312 & 152.89 & \\
\hline Total & 56550.5 & 319 & & \\
$*=\mathrm{P}<0.05 ; * *=\mathrm{P}<0.01 ; \mathrm{ns}=$ & not significant. & \\
\hline
\end{tabular}

The present results showed that regardless of gender and residence, adolescents with service background have evaluated the out-group less positively as compared to the adolescent with business background. This finding has provided confirmation to the hypothesis formulated in this respect. One possible reason of this finding might be that people with business background come in contact with a large number of people including males and females of homogeneous environmental background. This finding has its theoretical support with contact theory formulated by Amir (1969, 1976). The proponents of contact theory of intergroup relations hold the idea that the contact between the members of different social groups would help to understand each other and would diminish prejudice by lowering down the social distance among them. Adolescents with service background have relations with people of a homogeneous environment and as a consequence an introvert characteristic pattern develops among them. This introvert characteristic pattern of personality might be the cause for less contact with the out-group members leading to lowering down the out-group evaluation.

The Second prediction was that adolescent girls would evaluate out-group members less positively as compared to the adolescent boys. This hypothesis has also been confirmed by the results of the present study. It has been demonstrated that regardless of parental occupation and residence, girls evaluated out-group less positively as compared to the boys. Gender differences in out-group evaluation are based on biology, learning or some combinations of the two. Socialization process in outgroup evaluation in terms of gender differences is also a more important determinant (Martin and Parker 1995). Women, whose lives have been spent experiencing social and mental pressure, deal with out-group members in an aggressive and hostile manner than man. Pliner et al. (1974) found that women are much more likely to be concerned about their body image, to express dissatisfaction about their bodies and about physical appearance. As a consequence they are more likely to blame themselves and tend to attribute less positive evaluation to out-group members than do men. Thompson et al. (1995) found that the day-to-day negative of the special emphasis our society places on the physical attractiveness of women in general and specific anatomical details. The consequence is that women often are vulnerable and easily upset when their appearance becomes an issue and because of this they tend to avoid social interaction with out-group members and evaluate them less positively than men. Men described themselves as more assertive than women and compared to men, women respond with greater emotional intensity and by physiological assessment. These differences in men and women caused by biological, social or a combination of these factors might be responsible for difference in evaluation patterns for the out-group.

The third prediction was that adolescents with urban residential background would evaluate out-group less positively as compared to the adolescents with rural residential background. The findings of this study have provided confirmation to this hypothesis also. It has been found that respondents with urban residential background evaluated out-group less positively as compared to the respondents with rural residential background. This is closely related with the theoretical assumption that urban society is more competitive than the rural society. People in rural residential areas live simple lives characterized by mutual cooperation leading to more positive evaluation for the out-group. People in urban residential areas live complex lives characterized by competitiveness leading to less positive evaluation for the out-group. People in urban residential areas live complex lives characterized by competitiveness leading to less positive evaluation for the out-group. It is thus plausible that rural people having a traditional way of living show more positive evaluation for the out-group. Similarly, urban people having an industrialized structure of living show less positive evaluation for the out-group. 


\section{Conclusion}

Important findings of the present study are: (1) adolescents of urban residential background with business environment evaluated out-group significantly less positively as compared to the adolescents of rural residential background with business environment. Thus in case of parental business, the adolescents of urban and rural residential background showed significant variation in their out-group evaluation; (2) in case of urban residential background, adolescents with business environment evaluated out-group more positively as compared to the adolescents with service environment; and (3) the case was reverse in respect of rural residential background, where adolescents with service environment evaluated out-group less positively as compared to the adolescents with business environment. However, no difference was obtained in out-group evaluation between urban and rural adolescents in respect of parental service. These findings show that intergroup relations are determined by a large number of social and psychological factors and out-group evaluation may be accepted as determinant of social identity.

\section{References}

Amir Y. 1969. Contact hypothesis in ethnic relations. Psychol. Bull. 71: 319-342.

Amir Y. 1976. The Role of inter group contact in change of prejudice and ethnic relations. In: Toward the Elimination of Racism (PA Katz ed.), pp. 245-308, Pergamon, New York.

Billig M. 1971. Social Categorization and Intergroup Relations. Unpubl. Ph.D. Thesis, University of Bristol, UK.

Commins B and Lockwood J. 1979. The effects of status differences favored treatments and equity on intergroup comparisons. European J. Social Psychol. 9: 281-289.

Ehrlich HJ. 1973. The Social Psychology of Prejudice: A systematic theoretical review and propositional Inventory of the American Social Psychological Study of Prejudice. 117-141 pp. Basil Blackwell, New York.

Ellemers N and van Knippenberg AD. 1997. Stereotyping in Social Context. In: The Social Psychology of Stereotyping and Group Life (Spears R, Oakes PJ, Ellemers $\mathrm{N}$ and Haslam SA eds), pp. 208-235, Blackwell, Cambridge, MA.

Ethier KA and Deaux K. 1994. Negotiating social identity when contexts change: Maintaining identification and responding to threat. J. Per. Social Psychol. 67: 243-251
Freese L and Burke PJ. 1994. Persons, Identities and Social Interaction. In: Advances in Group Processes (Markovsdy B, Karen Heimer K, and O’Brien J eds.), pp. 1-24, JAI, Greenwich, CT.

Haslam SA, Oakes PJ, McGarty C, Turner JC, Reynolds KJ and Eggins RA. 1996. Stereotyping and social Influence: The Mediation of stereotypes applicability and shared ness by the views of in-group members. $J$. Social Psychol. 35: 369-97.

Hogg MA, Terry DJ, and White KM. 1995. A tale of two theories: A critical comparison of identity theory with social identity theory. Social Psychol. Quart. 58: 255-69.

Kidder LH and Stewart VM. 1975. The Psychology of Relations: Conflict and Consciousness. McGraw-Hill, New York.

Levine RA and Campbell DT. 1972. Ethnocentrism: Theories of Conflict, Ethnic attitudes and Group Behaviour. John Wiley and Sons, Inc., New York.

Majeed A and Ghosh ESK. 1982. A study of social identity in three ethnic groups in India. Intl. J. Ppsychol. 17: 455463.

Martin CL and Parker S. 1995. Folk theories about sex and race differences. Per. Social Psychol. Bull. 21: 45-57.

Oakes PJ, Haslam SA and Turner JC. 1994. Stereotypes and Social Reality. Basil Blackweell, Oxford, UK.

Pliner P, Hart H, Kohl J and Saari D. 1974. Compliance without pressure: Some further data on the foot-in-the-door technique. J. Exp. Social Psychol. 10: 17-22.

Sherif M. 1966. Common Predicament: Social Psychology of Intergroup Conflict and Cooperation . Haughton Miffin, Boston, USA.

Stryker S and Serpe RT. 1994. Identity salience and psychological centrality: Equivalent, overlapping, or complementary concepts? Social Psychol. Quart. 57: 16-35.

Tajfel H. (ed) 1978. Differentiation Between Social Groups: Studies in the Social Psychology of Intergroup Relations. Academic Press, London, UK.

Tajfel H. 1981. Human Groups and Social Categories: Studies in Social Psychology. Cambridge University Press, Cambridge.

Thompson JM, Whitten VE and Blain MD. 1995. Depressive symptoms, sex and perceptions of intimate relationships. J. Social Per. Rel. 12: 49-66.

Turner J, Hogg MA, Oakes PJ, Reicher SD and Wetherell MS. 1987. Rediscovering the Social Group: A Self Categorization Theory. Basil Blackwell, New York.

Manuscript received on 12 April 2010 and revised on 19 December 2010 